\title{
PERFIL SENSORIAL E TESTE DE CONSUMIDOR DE BISCOITO RECHEADO SABOR CHOCOLATE
}

\author{
RITA DE CÁSSIA S. CELESTE ORMENESE * \\ DANIELA ARRUDA MARCHESE * \\ MOACIR EVANDRO LAGE * \\ MARIA EUGÊNIA DE OLIVEIRA MAMEDE * \\ GLÁUCIA MARIA NAVARRO ABREU * \\ HELLEN DANIELA COELHO * \\ JULIANA M. L. N. MOURA * \\ LUCIANA ÉRICA NISHI * \\ NEIDE APARECIDA CARRILHO * \\ NORKA BEATRIZ GONZÁLEZ * \\ MARIA APARECIDA AZEVEDO PEREIRA DA SILVA **
}

\begin{abstract}
O objetivo deste trabalho foi construir o perfil sensorial de três marcas comerciais de biscoito recheado sabor chocolate, líderes no mercado consumidor. Empregou-se a análise descritiva quantitativa (ADQ) para avaliar os atributos sensoriais dos produtos e aplicou-se teste de consumidor para verificar quais atributos determinam sua aceitação e preferência junto ao mercado. Concluiu-se que as amostras que competem no mercado são muito distintas em suas características sensoriais. O biscoito que apresentou melhor aceitação pelos consumidores evidenciou que atributos como aroma e sabor de cacau, crocância, baixa arenosidade do recheio, boa dissolução e pouca resistência à mordida são características bastante importantes para a determinação da preferência no mercado.
\end{abstract}

PALAVRAS-CHAVE: BISCOITO; ANÁLISE DESCRITIVA QUANTITATIVA; ANÁLISE SENSORIAL.

* Alunos de Pós-graduação da Faculdade de Engenharia de Alimentos (FEA), Universidade de Campinas (UNICAMP), Campinas, SP.

** Professora, Departamento de Planejamento Alimentar e Nutrição, UNICAMP, Campinas, SP. (e-mail: ritaorm@ital.org.br). 


\section{INTRODUÇÃO}

Os biscoitos pertencem ao grupo de alimentos não-essenciais, sendo classificados como alimento tipo lanche ("snack"). São produzidos pelo aprisionamento de ar dentro de base de amido e matriz oleosa para criar texturas que variam de leves, macias ou mastigáveis para crocantes, friáveis ou folhadas (BROWN, LANGLEY \& BRAXTON, 1998). Este tipo de produto é largamente consumido e apresenta vida-de-prateleira relativamente longa, além de adequada qualidade como alimento. Os biscoitos podem ser fortificados com proteínas vegetais ou animais combinadas ou de forma individual. Mesmo vegetais de folhas verdes podem ser incorporados, devido à sua riqueza em vitaminas e minerais (GOYLE \& GUJRAL, 1992).

Alguns ingredientes assumem importância destacada na qualidade dos biscoitos. O açúcar, por exemplo, contribui tanto para sua textura, sabor e doçura como para a cor do biscoito. A quantidade, granulação e tipo de açúcar usado influencia muito a qualidade do produto. O aumento da concentração de açúcar geralmente aumenta o espalhamento e reduz a espessura dos biscoitos. A quantidade limitada de água usada na formulação e sua indisponibilidade para a proteína e o amido contribui para a crocância (MANOHAR \& RAO, 1997).

Os biscoitos são, geralmente, consumidos para satisfazer necessidades hedônicas e não nutricionais. Conseqüentemente, a qualidade sensorial é o principal fator na determinação da aceitação e preferência do consumidor por estes produtos, devendo-se conhecer os parâmetros sensoriais considerados importantes pelo consumidor. BROWN et al. (1998) cita que para biscoitos planos a textura é crítica, tanto para a preferência como para as expectativas com respeito ao tipo particular ou marca.

Este trabalho teve como finalidade a comparação de três marcas comerciais de biscoitos recheados de chocolate, largamente difundidas no mercado brasileiro, estabelecendo atributos sensoriais e avaliando a preferência do consumidor.

\section{MATERIAL E MÉTODOS}

Três marcas comerciais de biscoito recheado sabor chocolate (A, B e C) foram avaliadas, tendo sido codificadas com números de três dígitos. 


\subsection{ANÁLISE SENSORIAL}

\subsubsection{Análise Descritiva Quantitativa (ADQ)}

Inicialmente, dez provadores foram escolhidos dentre os alunos do curso de Análise Sensorial e Instrumental de Alimentos do Departamento de Planejamento Alimentar e Nutrição da Faculdade de Engenharia de Alimentos (FEA) da Universidade de Campinas.

O perfil sensorial de cada amostra foi determinado por provadores selecionados e treinados, segundo a metodologia de análise descritiva quantitativa (STONE \& SIDEL, 1993).

Todos os testes sensoriais foram realizados no Laboratório de Análise Sensorial da FEA, em cabines individuais, com utilização de iluminação branca para avaliação da aparência e iluminação vermelha para avaliação de aroma, sabor e textura.

A obtenção da lista de descritores, bem como o treinamento dos provadores ocorreu mediante mesa redonda, realizando-se discussões abertas, sob a coordenação de um líder com conhecimento teórico e prático sobre o produto.

\subsubsection{Desenvolvimento de Terminologia Descritiva}

O desenvolvimento de terminologia descritiva das amostras de biscoito recheado sabor chocolate obedeceu o Método de Rede (MOSKOWITZ, 1983), sendo os produtos apresentados aos provadores em cabines individuais de avaliação sensorial. Os componentes da equipe foram solicitados a avaliar as amostras, utilizando a Ficha de Aplicação do Método de Rede para o Desenvolvimento da Terminologia Descritiva (Figura 1).

Após cada provador ter gerado seus próprios termos para descrever as similaridades e as diferenças entre as amostras ocorreu discussão em grupo, conduzida sob supervisão do líder, com o objetivo de agrupar termos descritivos semelhantes e gerar amostras de referência. Sessões suplementares de avaliação das amostras, das referências e de discussão em grupo resultaram no uso consensual de termos descritivos pela equipe sensorial e na elaboração da Ficha para Avaliação Sensorial de Biscoitos Recheados Sabor Chocolate Mediante Teste de Aceitação (Figura 2). 
Para maior compreensão e consenso dos provadores foram estabelecidas definições de cada termo descritivo pela equipe sensorial (Quadro1).

\title{
FIGURA 1 - FICHA DE APLICAÇÃO DO MÉTODO DE REDE PARA O DESENVOLVIMENTO DE TERMINOLOGIA DESCRITIVA
}

\begin{abstract}
Nome:
Data:

Você está recebendo três amostras codificadas. Inicialmente, avalie a aparência das três amostras agrupando as duas mais similares. Em seguida, descreva em que são similares e em que diferem da terceira amostra. Repita esse procedimento para cada par de amostras. Em seguida, repita os mesmos procedimentos para aroma, sabor e textura.
\end{abstract}

APARÊNCIA

Amostras

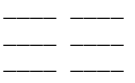

AROMA

Amostras

$\square-\square$

SABOR

Amostras

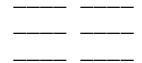

TEXTURA

Amostras
Similaridades

Diferenças

Similaridades

Diferenças

Similaridades

Diferenças

Similaridades

Diferenças

\subsubsection{Treinamento e Seleção da Equipe de Análise Descritiva}

Durante as sessões de treinamento, os provadores foram solicitados a avaliar a intensidade de cada atributo nas diferentes amostras utilizando a ficha de avaliação previamente desenvolvida pela equipe sensorial (Figura 2). Em cada sessão foram colocados à disposição dos provadores os materiais de referência e a definição de cada termo descritivo. 


\section{FIGURA 2 - FICHA PARA AVALIAÇÃO SENSORIAL DE BISCOITOS RECHEADOS SABOR CHOCOLATE MEDIANTE TESTE DE ACEITAÇÃO}

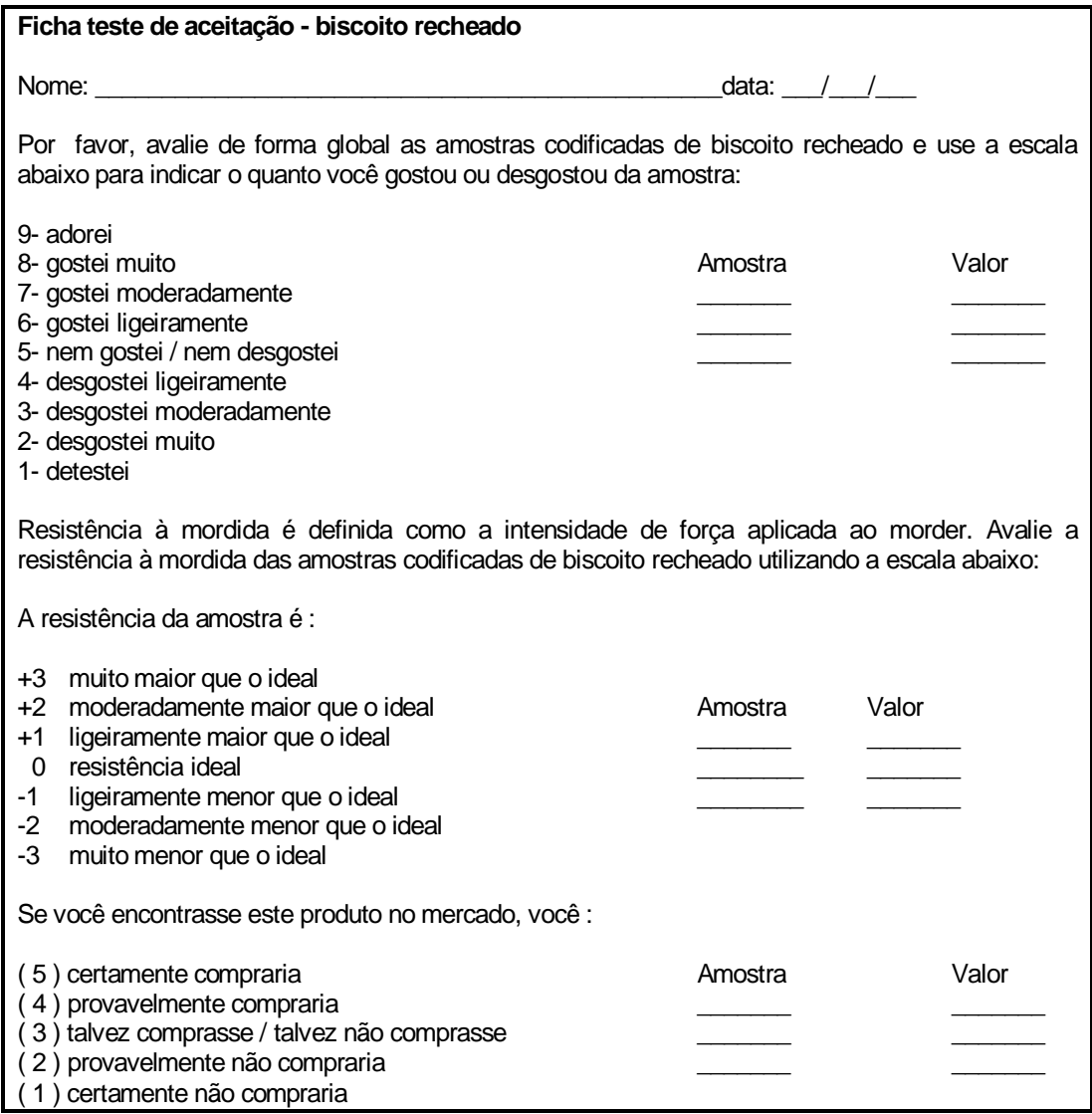

O treinamento dos provadores consistiu na avaliação das amostras de biscoito recheado sabor chocolate com três repetições. Cada atributo foi avaliado mediante escala não-estruturada de $9 \mathrm{~cm}$, ancorada nos extremos pelos termos de intensidade mínimo e máximo próprios de cada atributo. Utilizou-se delineamento experimental de blocos completos casualizados (MEILGAARD et al., 1991). 
Efetuou-se análise de variância para os resultados de cada provador (Fontes de Variação: amostras, repetições). Provadores que apresentaram bom poder discriminativo $\left(\mathrm{p}_{\text {amostra }} \leq 0.50\right)$, boa reprodutibilidade nos julgamentos $\left(p_{\text {repetiçoes }}>0.050\right)$ e consenso com os demais membros do grupo foram selecionados para compor a equipe descritiva treinada.

\subsubsection{Perfil Sensorial dos Biscoitos Recheados Sabor Chocolate}

O perfil sensorial das três amostras de biscoito recheado sabor chocolate foi determinado pelos 10 provadores treinados e selecionados conforme descrito anteriormente. Os resultados das avaliações dos provadores foram submetidos à Análise de Variância, Teste de Médias (TUKEY) e Análise de Componentes Principais (ACP) pelo programa estatístico SAS (1985).

\subsection{TESTE DE ACEITAÇÃO DOS BISCOITOS RECHEADOS SABOR CHOCOLATE}

O teste de aceitação foi realizado com 42 provadores que avaliaram as 3 amostras de biscoito recheado, analisando-se a aceitação global do produto, a intenção de compra e a resistência à mordida das amostras. Para a aceitação global empregou-se o teste de escala hedônica estruturada mista, para resistência à mordida o teste de escala do ideal e para intenção de compra a escala estruturada mista com cinco pontos (Figura 2).

\section{RESULTADOS E DISCUSSÃO}

\subsection{ANÁLISE DESCRITIVA QUANTITATIVA (ADQ)}

\subsubsection{Terminologia descritiva e referências utilizadas na avaliação sensorial}

Os vinte e sete termos desenvolvidos pelos provadores para descrever as similaridades e diferenças entre as amostras de biscoito sabor chocolate são mostrados no Quadro 1.

A Figura 3 apresenta a Ficha de Avaliação Sensorial de Amostras elaborada a partir dos termos definidos pela equipe sensorial. 
QUADRO 1-DEFINIÇÃO DOS TERMOS DESCRITIVOS E REFERÊNCIAS USADAS COMO EXTREMOS DE ESCALA DE INTENSIDADE NA ADQ DE BISCOITO RECHEADO SABOR CHOCOLATE PARA OS ATRIBUTOS DE APARÊNCIA, AROMA, SABOR E TEXTURA

\begin{tabular}{|c|c|c|c|c|}
\hline ASPECTO & DESCRITIVO & DEFINIÇÃO & $\begin{array}{l}\text { REFERÊNCIA } \\
\text { MÍNIMA }\end{array}$ & REFERÊNCIA MÁXIMA \\
\hline \multirow{6}{*}{ Aparência } & Cor creme & $\begin{array}{l}\text { Intensidade da cor } \\
\text { creme }\end{array}$ & $\begin{array}{l}\text { Farinha de trigo } \\
\text { especial - Anhanguera }\end{array}$ & $\begin{array}{l}\text { Bala de caramelo - } \\
\text { Embaré }\end{array}$ \\
\hline & $\begin{array}{l}\text { Uniformidade da } \\
\text { superfície }\end{array}$ & $\begin{array}{l}\text { Superfície superior } \\
\text { sem trincas }\end{array}$ & $\begin{array}{l}\text { Biscoito Cookie - } \\
\text { Nabisco }\end{array}$ & $\begin{array}{l}\text { Biscoito Negresco } \\
\text { coberto- São Luiz }\end{array}$ \\
\hline & Espessura da base & Altura da base & $\begin{array}{l}\text { Biscoito Acqua - } \\
\text { Tostines }\end{array}$ & $\begin{array}{l}\text { Biscoito Cookie - } \\
\text { Nabisco }\end{array}$ \\
\hline & $\begin{array}{l}\text { Uniformidade da } \\
\text { cor }\end{array}$ & $\begin{array}{l}\text { Distribuição da cor } \\
\text { creme na superfície } \\
\text { superior }\end{array}$ & $\begin{array}{l}\text { Biscoito Cream } \\
\text { cracker - Tostines }\end{array}$ & $\begin{array}{l}\text { Biscoito Wafer morango } \\
- \text { Tostines }\end{array}$ \\
\hline & $\begin{array}{l}\text { Cor marrom do } \\
\text { recheio }\end{array}$ & $\begin{array}{l}\text { Intensidade da cor } \\
\text { marrom }\end{array}$ & Cacau em pó marrom & Cacau em pó preto \\
\hline & $\begin{array}{l}\text { Quantidade de } \\
\text { recheio }\end{array}$ & $\begin{array}{l}\text { Relação espessura/ } \\
\text { diâm etro sobre a } \\
\text { base }\end{array}$ & $\begin{array}{l}\text { Biscoito fabricado com } \\
17 \% \text { de recheio }\end{array}$ & $\begin{array}{l}\text { Biscoito fabricado com } \\
37 \% \text { de recheio }\end{array}$ \\
\hline \multirow{6}{*}{ Aroma } & Baunilha & $\begin{array}{l}\text { Intensidade do } \\
\text { aroma associado à } \\
\text { baunilha }\end{array}$ & & $\begin{array}{l}\text { Essência de baunilha } \\
\text { Givaudan diluída em } \\
\text { água a } 0,3 \%\end{array}$ \\
\hline & Cacau & $\begin{array}{l}\text { Intensidade do } \\
\text { aroma associado ao } \\
\text { cacau em pó }\end{array}$ & & $\begin{array}{l}\text { Cacau em pó diluído em } \\
\text { água a } 5 \%\end{array}$ \\
\hline & Leite & $\begin{array}{l}\text { Intensidade do } \\
\text { aroma associado ao } \\
\text { leite em pó integral }\end{array}$ & & Leite em pó integral \\
\hline & Manteiga & $\begin{array}{l}\text { Intensidade do } \\
\text { aroma associado à } \\
\text { manteiga }\end{array}$ & & $\begin{array}{l}\text { Aroma de manteiga } \\
\text { diluído em água a } 0,1 \%\end{array}$ \\
\hline & Torrado & $\begin{array}{l}\text { Intensidade do } \\
\text { aroma associado a } \\
\text { produto de } \\
\text { panificação }\end{array}$ & & $\begin{array}{l}\text { Biscoito Cream cracker - } \\
\text { Tostines }\end{array}$ \\
\hline & Farinha de trigo & $\begin{array}{l}\text { Intensidade do } \\
\text { aroma associado à } \\
\text { farinha de trigo }\end{array}$ & & $\begin{array}{l}\text { Farinha de trigo especial } \\
\text { - Anhanguera }\end{array}$ \\
\hline
\end{tabular}

continua... 


\begin{tabular}{|c|c|c|c|c|}
\hline ASPECTO & DESCRITIVO & DEFINIÇÃO & $\begin{array}{l}\text { REFERÊNCIA } \\
\text { MÍNIMA }\end{array}$ & REFERÊNCIA MÁXIMA \\
\hline \multirow{10}{*}{ Sabor } & Doçura & $\begin{array}{l}\text { Intensidade do gosto } \\
\text { associado à } \\
\text { sacarose }\end{array}$ & $\begin{array}{l}\text { Solução de sacarose } \\
\text { a } 5 \%\end{array}$ & $\begin{array}{l}\text { Solução de sacarose a } \\
30 \%\end{array}$ \\
\hline & Cacau & $\begin{array}{l}\text { Intensidade do sabor } \\
\text { associado ao cacau } \\
\text { em pó }\end{array}$ & $\begin{array}{l}\text { Diluição de cacau em } \\
\text { pó em água a 0,5\% }\end{array}$ & $\begin{array}{l}\text { Diluição de cacau em pó } \\
\text { em água a } 5 \%\end{array}$ \\
\hline & Baunilha & $\begin{array}{l}\text { Intensidade do sabor } \\
\text { associado à } \\
\text { essência de } \\
\text { baunilha }\end{array}$ & & $\begin{array}{l}\text { Essência de baunilha } \\
\text { Givaudan diluída em } \\
\text { água a } 0,3 \%\end{array}$ \\
\hline & Manteiga & $\begin{array}{l}\text { Intensidade do sabor } \\
\text { associado à } \\
\text { manteiga }\end{array}$ & & $\begin{array}{l}\text { Aroma de manteiga } \\
\text { diluído em água a 0,1\% }\end{array}$ \\
\hline & Leite & $\begin{array}{l}\text { Intensidade do sabor } \\
\text { associado ao leite } \\
\text { em pó integral }\end{array}$ & & Leite em pó integral \\
\hline & Farinha de trigo & $\begin{array}{l}\text { Intensidade do sabor } \\
\text { associado à farinha } \\
\text { de trigo crua }\end{array}$ & & $\begin{array}{l}\text { Farinha de trigo especial } \\
\text { - Anhanguera }\end{array}$ \\
\hline & Salgado & $\begin{array}{l}\text { Intensidade do gosto } \\
\text { associado ao cloreto } \\
\text { de sódio }\end{array}$ & Água pura & Solução $1 \%$ de $\mathrm{NaCl}$ \\
\hline & Assado/ torrado & $\begin{array}{l}\text { Intensidade do sabor } \\
\text { associado com } \\
\text { produto de } \\
\text { panificação }\end{array}$ & & $\begin{array}{l}\text { Biscoito Cream cracker - } \\
\text { Tostines }\end{array}$ \\
\hline & Avelã & $\begin{array}{l}\text { Intensidade do sabor } \\
\text { associado à avelã }\end{array}$ & & Avelã crua \\
\hline & Gordura vegetal & $\begin{array}{l}\text { Intensidade do sabor } \\
\text { residual associado à } \\
\text { gordura vegetal } \\
\text { hidrogenada }\end{array}$ & & $\begin{array}{l}\text { Gordura vegetal } \\
\text { hidrogenada }\end{array}$ \\
\hline
\end{tabular}

continua.... 
continuação

\begin{tabular}{|c|c|c|c|c|}
\hline ASPECTO & DESCRITIVO & DEFINIÇÃO & $\begin{array}{l}\text { REFERÊNCIA } \\
\text { MÍNIMA }\end{array}$ & REFERÊNCIA MÁXIMA \\
\hline \multirow{4}{*}{ Textura } & $\begin{array}{l}\text { Resistência à } \\
\text { mordida }\end{array}$ & $\begin{array}{l}\text { Intensidade de força } \\
\text { aplicada ao morder }\end{array}$ & $\begin{array}{l}\text { Biscoito Wafer } \\
\text { morango - Tostines }\end{array}$ & Biscoito de coco Xereta \\
\hline & Crocância & $\begin{array}{l}\text { Intensidade da força } \\
\text { com que o alimento } \\
\text { "pula" dos seus } \\
\text { dentes ao ser } \\
\text { mordido, associado } \\
\text { à sensação auditiva }\end{array}$ & $\begin{array}{l}\text { Rosquinha de } \\
\text { chocolate Doribon }\end{array}$ & $\begin{array}{l}\text { Biscoito Cream cracker - } \\
\text { Tostines }\end{array}$ \\
\hline & Dissolução & $\begin{array}{l}\text { Sensação do } \\
\text { desmanche do } \\
\text { biscoito na boca }\end{array}$ & $\begin{array}{l}\text { Biscoito Acqua - } \\
\text { Tostines }\end{array}$ & $\begin{array}{l}\text { Barra de chocolate ao } \\
\text { leite }\end{array}$ \\
\hline & $\begin{array}{l}\text { Arenosidade do } \\
\text { recheio }\end{array}$ & $\begin{array}{l}\text { Sensação associada } \\
\text { com a presença de } \\
\text { grânulos no recheio }\end{array}$ & $\begin{array}{l}\text { Barra de chocolate ao } \\
\text { leite }\end{array}$ & $\begin{array}{l}\text { Recheio do biscoito } \\
\text { Nescau }\end{array}$ \\
\hline
\end{tabular}

\section{FIGURA 3 - FICHA DE AVALIAÇÃO SENSORIAL DE AMOSTRAS DE BISCOITOS RECHEADOS SABOR CHOCOLATE}

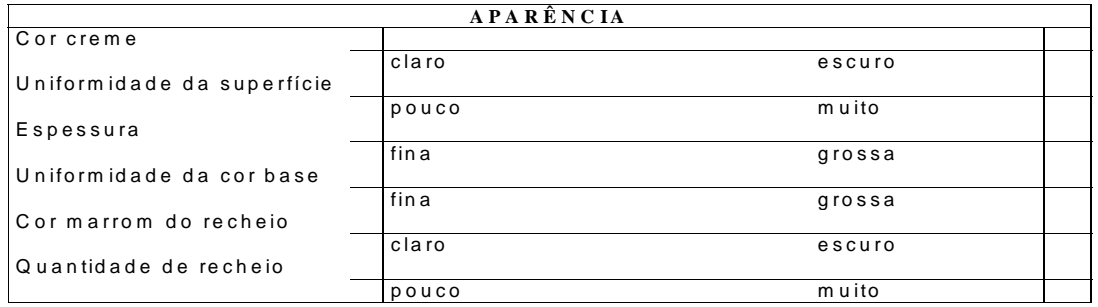

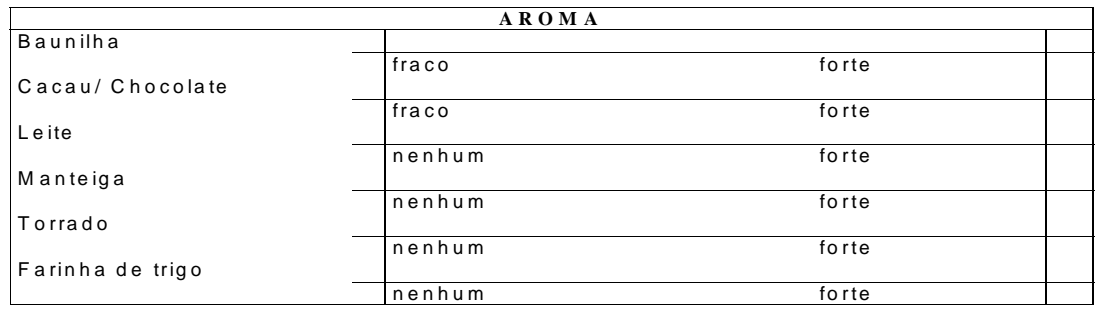

continua... 
continuação

\begin{tabular}{|c|c|c|c|}
\hline \multicolumn{4}{|c|}{ SABOR } \\
\hline Doçura & & & \\
\hline Cacau/ Chocolate & pouco & muito & \\
\hline Baunilha & fraco & forte & \\
\hline Manteiga & nenhum & forte & \\
\hline Leite & nenhum & forte & \\
\hline Farinha de trigo & nenhum & forte & \\
\hline Salgado & nenhum & forte & \\
\hline Assado/ Torrado & nenhum & forte & \\
\hline Avelã & nenhum & forte & \\
\hline Gordura Vegetal & nenhum & forte & \\
\hline & nenhum & forte & \\
\hline
\end{tabular}

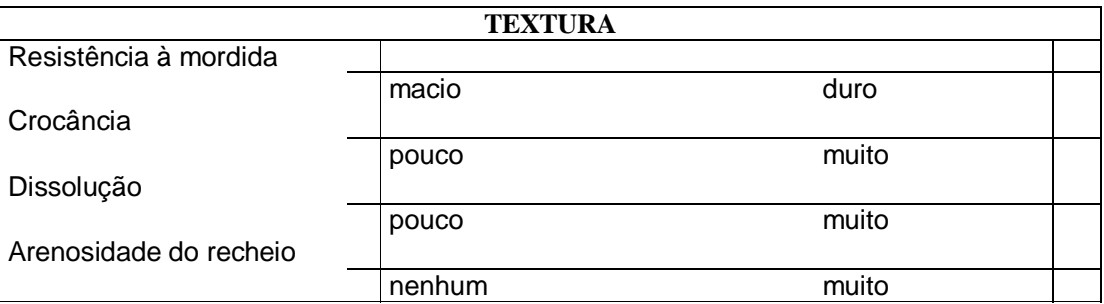

\subsubsection{Seleção de provadores}

Todos os provadores apresentaram capacidade de discriminação dos atributos avaliados (Tabela 1) e consenso com a equipe na maioria dos atributos (Tabela 2). Os atributos que não foram bem discriminados pela equipe, devido à falta de consenso entre os provadores, foram eliminados uma vez que não haveria tempo para intensificar o treinamento para estes atributos. Como a repetibilidade é o terceiro parâmetro a ser considerado na seleção final da equipe, a pouca habilidade de alguns provadores (Tabela 1) não foi levada em consideração. 

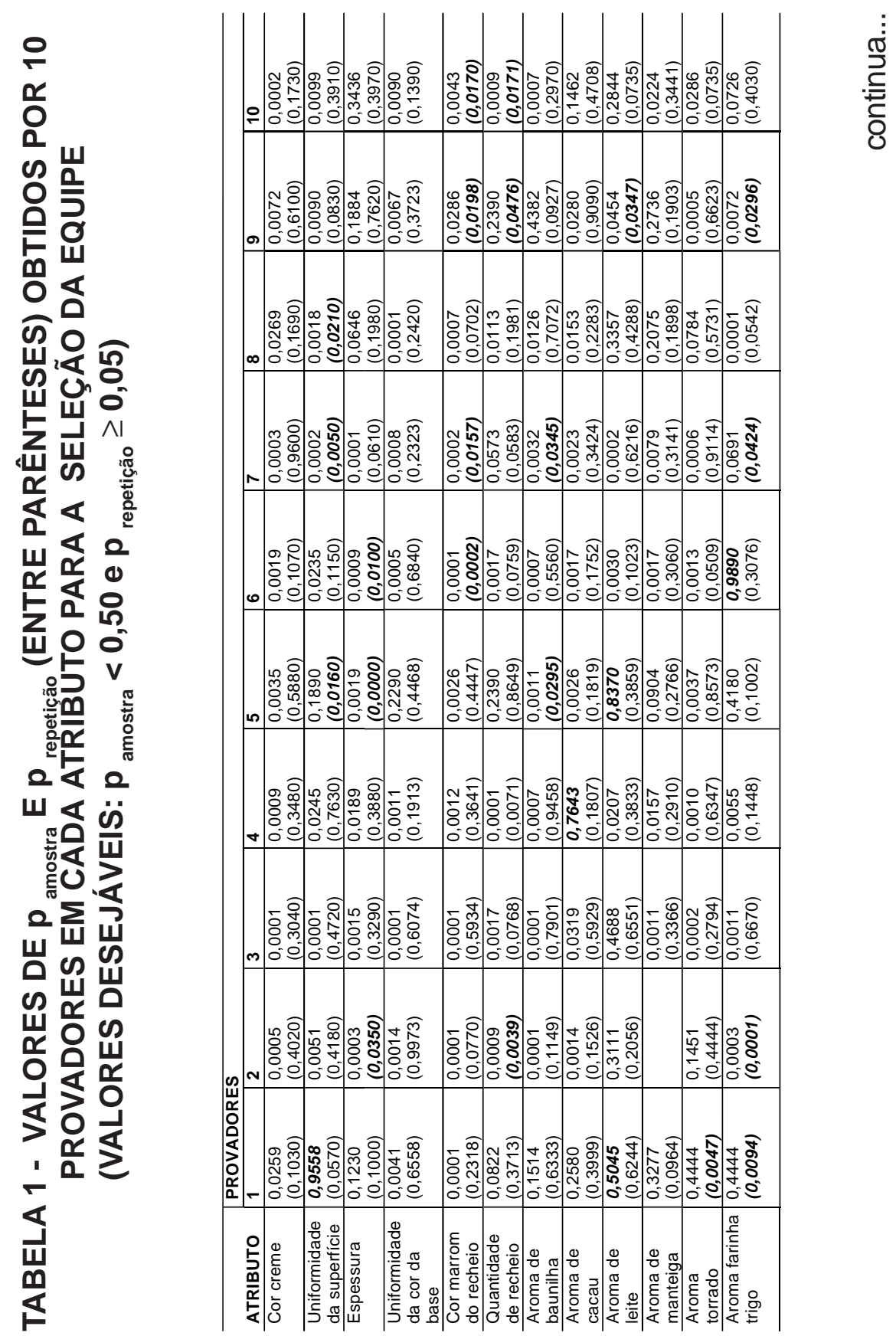

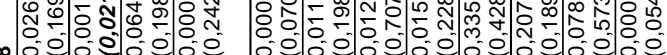
\begin{tabular}{lll|l|l|l|l|l|l|l|l|l|l}
\hline & & & & & & & & & & & & \\
\hline
\end{tabular}

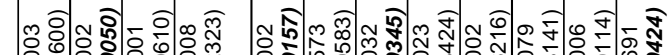
N

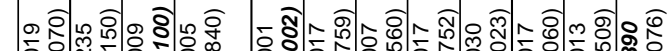

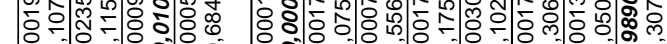

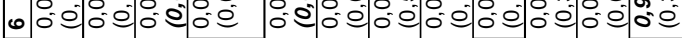

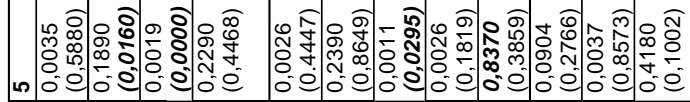

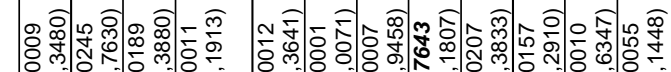

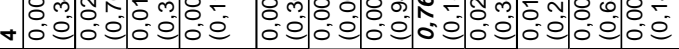

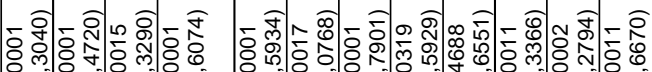

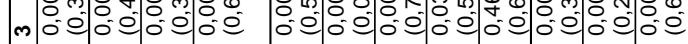

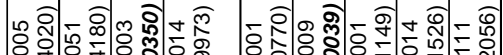

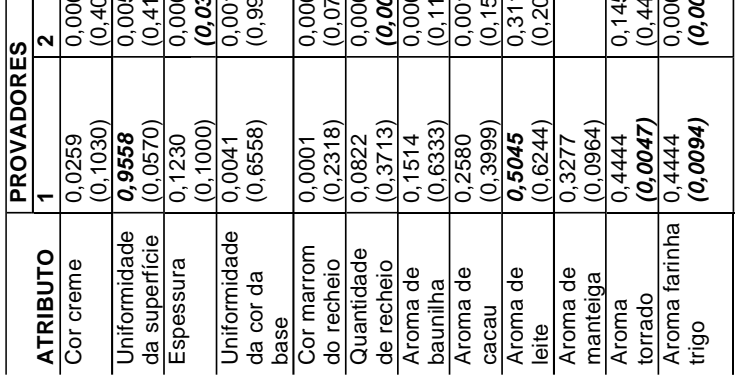




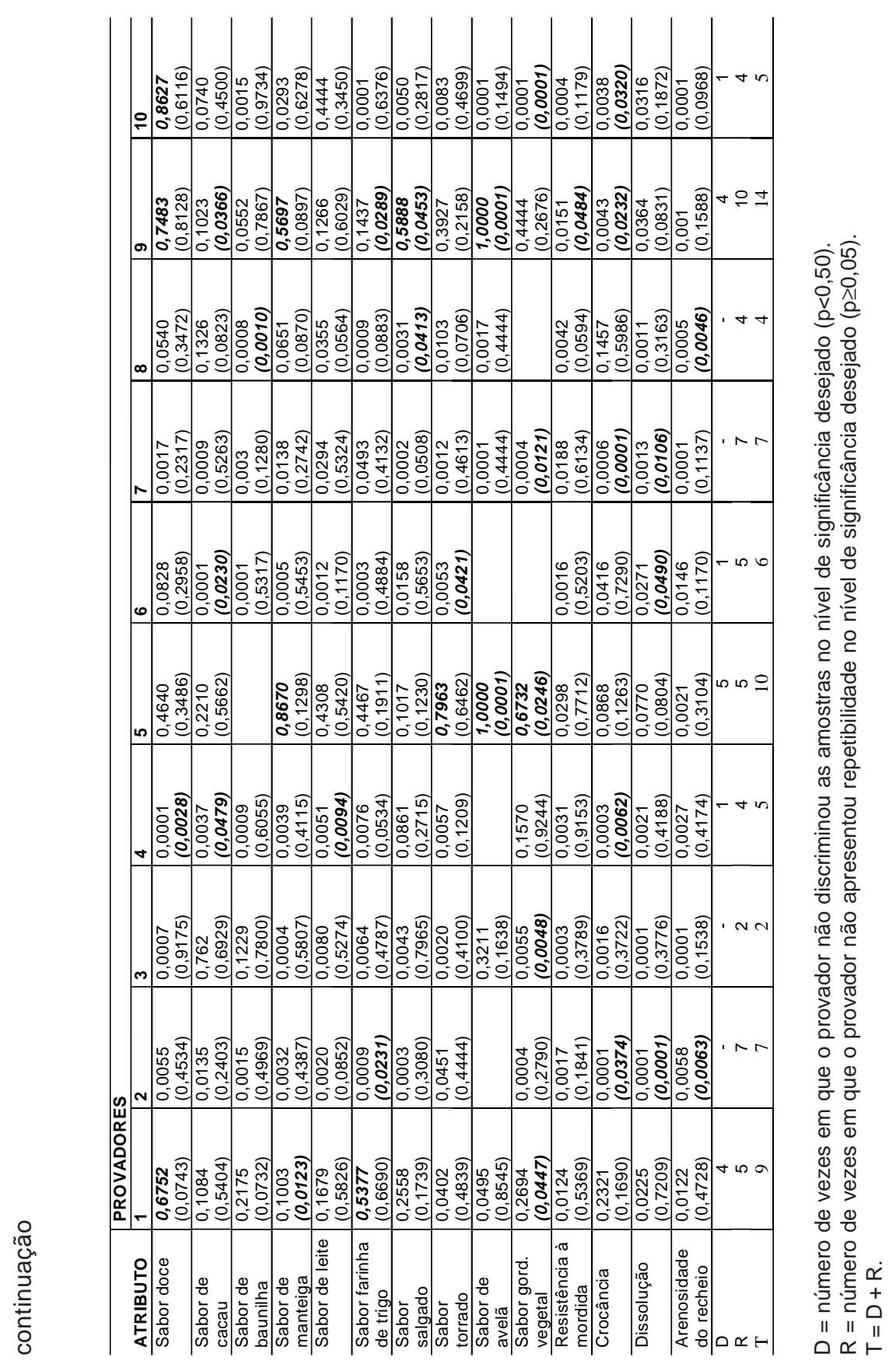




\section{TABELA 2 - MÉDIAS DAS NOTAS DE CADA PROVADOR E DA EQUIPE SENSORIAL PARA CADA ATRIBUTO AVALIADO}

\begin{tabular}{|c|c|c|c|c|c|c|c|c|c|c|c|c|}
\hline Atributo & $\begin{array}{c}\text { Amos- } \\
\text { tra }\end{array}$ & Equipe & P1 & P2 & P3 & P4 & P5 & P6 & P7 & P8 & P9 & P10 \\
\hline & $A$ & $1,423 \mathrm{c}$ & 2,700 & 0,966 & 0,333 & 0,866 & 0,566 & 2,033 & 1,633 & 1,200 & 3,266 & 0,666 \\
\hline \multirow[t]{2}{*}{ Cor creme } & B & $3,760 \mathrm{~b}$ & 4,133 & 4,066 & 4,200 & 3,066 & 2,533 & 4,600 & 2,700 & 3,133 & 4,900 & 4,266 \\
\hline & C & $6,420 \mathrm{a}$ & 7,833 & 7,100 & 8,566 & 6,333 & 5,166 & 6,033 & 4,966 & 5,166 & 6,066 & 6,966 \\
\hline Uniformidade & A & $6,883 a$ & 5,900 & 6,900 & 7,900 & 7,800 & 7,366 & 7,066 & 6,733 & 5,966 & 5,700 & 7,500 \\
\hline \multirow{2}{*}{ superfície } & B & $4,920 \mathrm{~b}$ & 5,467 & 3,800 & 8,166 & 3,467 & 6,466 & 4,133 & 5,866 & 3,900 & 3,166 & 4,766 \\
\hline & C & $3,500 \mathrm{c}$ & 5,833 & 2,033 & 0,566 & 4,100 & 6,166 & 3,566 & 4,966 & 2,100 & 3,066 & 2,600 \\
\hline & $A$ & $2,663 c$ & 4,800 & 1,466 & 0,800 & 1,766 & 6,033 & 3,533 & 0,933 & 1,166 & 3,066 & 3,067 \\
\hline \multirow[t]{2}{*}{ Espessura } & B & $3,560 \mathrm{~b}$ & 5,366 & 2,166 & 3,166 & 2,266 & 6,500 & 4,466 & 2,266 & 1,966 & 3,866 & 3,567 \\
\hline & C & $5,656 a$ & 7,266 & 6,033 & 8,566 & 5,433 & 7,100 & 5,600 & 3,133 & 4,300 & 3,900 & 5,233 \\
\hline \multirow{3}{*}{$\begin{array}{l}\text { Uniformidade } \\
\text { da cor da base }\end{array}$} & A & $7,303 \mathrm{a}$ & 8,166 & 6,700 & 8,333 & 6,900 & 8,366 & 7,700 & 5,933 & 7,300 & 5,600 & 8,033 \\
\hline & B & $3,383 b$ & 5,666 & 3,400 & 4,866 & 2,066 & 5,400 & 3,466 & 2,766 & 1,500 & 2,666 & 2,033 \\
\hline & C & $3,013 b$ & 1,733 & 1,533 & 0,533 & 4,633 & 6,300 & 1,766 & 1,866 & 3,733 & 3,066 & 4,966 \\
\hline \multirow{3}{*}{$\begin{array}{l}\text { Cor marrom } \\
\text { do recheio }\end{array}$} & $A$ & $6,016 a$ & 8,566 & 5,233 & 8,300 & 5,200 & 6,600 & 7,133 & 4,833 & 5,533 & 4,400 & 4,366 \\
\hline & B & $5,850 \mathrm{a}$ & 8,733 & 6,500 & 8,000 & 5,466 & 6,133 & 6,100 & 4,633 & 5,600 & 4,600 & 2,733 \\
\hline & C & $1,716 b$ & 0,133 & 2,233 & 0,566 & 1,600 & 1,900 & 2,433 & 2,366 & 1,533 & 2,900 & 1,500 \\
\hline \multirow{3}{*}{$\begin{array}{l}\text { Quantidade de } \\
\text { recheio }\end{array}$} & A & $3,233 c$ & 4,500 & 2,066 & 3,033 & 3,100 & 4,033 & 3,666 & 3,466 & 1,700 & 2,900 & 3,866 \\
\hline & B & $4,063 b$ & 4,533 & 2,933 & 2,766 & 3,366 & 6,066 & 4,666 & 4,133 & 3,400 & 3,666 & 5,100 \\
\hline & C & $5,930 \mathrm{a}$ & 8,500 & 4,533 & 8,300 & 6,566 & 7,633 & 6,166 & 2,333 & 4,600 & 3,666 & 7,000 \\
\hline \multirow{3}{*}{$\begin{array}{l}\text { Aroma de } \\
\text { baunilha }\end{array}$} & A & $1,606 \mathrm{c}$ & 2,033 & 2,266 & 1,166 & 1,633 & 1,366 & 0,866 & 1,466 & 0,700 & 4,167 & 0,400 \\
\hline & B & $4,463 b$ & 7,300 & 1,466 & 8,233 & 5,533 & 1,966 & 5,333 & 2,566 & 1,766 & 3,400 & 7,066 \\
\hline & C & $5,553 a$ & 3,000 & 7,266 & 7,833 & 6,900 & 6,200 & 6,600 & 3,733 & 4,200 & 5,033 & 4,766 \\
\hline \multirow{3}{*}{ Aroma de cacau } & $A$ & $3,043 b$ & 6,200 & 2,566 & 1,800 & 2,700 & 3,366 & 4,666 & 3,100 & 1,466 & 1,666 & 2,900 \\
\hline & B & $4,783 a$ & 8,300 & 6,100 & 8,100 & 3,700 & 4,066 & 3,466 & 5,300 & 3,000 & 0,400 & 5,400 \\
\hline & $\mathrm{C}$ & $2,743 b$ & 4,933 & 1,400 & 6,000 & 2,833 & 1,466 & 1,100 & 1,600 & 2,666 & 0,500 & 4,933 \\
\hline \multirow{3}{*}{ Aroma de leite } & A & $2,606 a$ & 5,700 & 2,633 & 8,400 & 0,600 & 0,766 & 0,033 & 6,433 & 0,500 & 0,833 & 0,166 \\
\hline & B & $2,72 \mathrm{a}$ & 7,767 & 2,266 & 5,567 & 4,000 & 0,300 & 3,600 & 1,700 & 1,000 & 0,433 & 0,566 \\
\hline & C & $2,85 \mathrm{a}$ & 7,033 & 0,966 & 5,700 & 1,966 & 0,000 & 5,133 & 5,500 & 1,033 & 0,266 & 0,900 \\
\hline \multirow{3}{*}{$\begin{array}{l}\text { Aroma de } \\
\text { manteiga }\end{array}$} & $A$ & $1,037 \mathrm{c}$ & 5,833 & $\mathrm{x}$ & 1,226 & 0,533 & 0,333 & 0,000 & 0,733 & 0,800 & 0,200 & 0,500 \\
\hline & B & $3,267 \mathrm{~b}$ & 6,633 & $\mathrm{x}$ & 6,966 & 2,666 & 1,000 & 2,800 & 3,666 & 2,232 & 0,133 & 4,500 \\
\hline & C & $4,445 \mathrm{a}$ & 8,067 & $\mathrm{x}$ & 8,166 & 4,933 & 3,700 & 4,900 & 3,200 & 2,833 & 0,700 & 5,733 \\
\hline \multirow{3}{*}{ Aroma torrado } & A & $0,803 c$ & 0,566 & 0,000 & 0,733 & 0,966 & 0,333 & 0,533 & 0,000 & 2,233 & 1,000 & 3,666 \\
\hline & B & $3,046 b$ & 0,566 & 0,000 & 5,300 & 1,633 & 1,266 & 3,433 & 5,666 & 1,933 & 4,766 & 5,900 \\
\hline & C & $4,120 \mathrm{a}$ & 0,700 & 0,866 & 8,400 & 6,700 & 4,033 & 4,733 & 5,866 & 1,800 & 0,633 & 7,466 \\
\hline \multirow{3}{*}{$\begin{array}{l}\text { Aroma } \\
\text { farinha de trigo }\end{array}$} & $A$ & $4,450 \mathrm{a}$ & 1,933 & 1,733 & 7,033 & 5,100 & 4,600 & 6,267 & 2,800 & 5,800 & 1,566 & 7,667 \\
\hline & B & $1,840 \mathrm{~b}$ & 1,333 & 1,266 & 2,333 & 0,466 & 4,100 & 3,533 & 0,266 & 1,833 & 0,533 & 2,733 \\
\hline & C & $2,620 \mathrm{~b}$ & 2,833 & 2,333 & 8,066 & 0,466 & 1,466 & 3,633 & 1,933 & 1,000 & 0,300 & 4,167 \\
\hline \multirow{3}{*}{$\begin{array}{l}\text { Aroma clara } \\
\text { de ovo }\end{array}$} & A & $0,03 a$ & 0,066 & 0,000 & 0,233 & 0,000 & 0,000 & 0,000 & 0,000 & 0,000 & 0,000 & 0,000 \\
\hline & B & $0,046 a$ & 0,066 & 0,000 & 0,400 & 0,000 & 0,000 & 0,000 & 0,000 & 0,000 & 0,000 & 0,000 \\
\hline & C & $0,066 a$ & 0,066 & 0,000 & 0,600 & 0,000 & 0,000 & 0,000 & 0,000 & 0,000 & 0,000 & 0,000 \\
\hline
\end{tabular}

continua.... 


\begin{tabular}{|c|c|c|c|c|c|c|c|c|c|c|c|c|}
\hline Atributo & $\begin{array}{c}\text { Amos- } \\
\text { tra }\end{array}$ & Equipe & P1 & P2 & P3 & P4 & P5 & P6 & P7 & P8 & P9 & P10 \\
\hline & $A$ & $3,816 b$ & 7,233 & 1,800 & 8,300 & 1,067 & 3,733 & 3,333 & 2,100 & 1,933 & 3,767 & 4,900 \\
\hline \multirow[t]{2}{*}{ Sabor doce } & B & $4,596 a$ & 6,800 & 3,200 & 7,300 & 3,700 & 3,467 & 4,766 & 5,400 & 2,666 & 3,333 & 5,333 \\
\hline & C & $5,140 \mathrm{a}$ & 7,433 & 5,833 & 1,566 & 5,166 & 6,766 & 5,200 & 4,966 & 4,533 & 4,500 & 5,433 \\
\hline \multirow{3}{*}{ Sabor de cacau } & $A$ & $5,493 a$ & 7,433 & 3,433 & 6,933 & 4,166 & 5,733 & 6,500 & 5,733 & 4,800 & 4,866 & 5,333 \\
\hline & B & $5,580 \mathrm{a}$ & 8,300 & 5,533 & 7,633 & 2,933 & 4,800 & 5,166 & 6,800 & 3,500 & 4,066 & 7,066 \\
\hline & C & $3,236 b$ & 7,266 & 1,900 & 3,633 & 1,400 & 1,366 & 1,766 & 4,900 & 2,833 & 2,366 & 4,933 \\
\hline & $A$ & $1,938 \mathrm{c}$ & 4,733 & 2,766 & 2,367 & 1,233 & $x$ & 0,900 & 0,000 & 1,900 & 2,333 & 7,766 \\
\hline Sabor de & B & $4,279 b$ & 8,267 & 1,933 & 4,400 & 5,366 & $x$ & 5,500 & 2,633 & 1,333 & 2,467 & 6,066 \\
\hline \multirow[t]{2}{*}{ baunilha } & C & $5,817 \mathrm{a}$ & 5,233 & 6,333 & 8,433 & 6,800 & $\mathrm{x}$ & 6,400 & 3,733 & 2,733 & 5,900 & 0,333 \\
\hline & $A$ & $2,960 \mathrm{~b}$ & 5,433 & 2,366 & 7,400 & 1,233 & 0,933 & 0,400 & 5,400 & 3,900 & 2,200 & 5,233 \\
\hline \multirow{3}{*}{$\begin{array}{l}\text { Sabor de } \\
\text { manteiga }\end{array}$} & B & $3,250 \mathrm{~b}$ & 6,400 & 2,366 & 1,400 & 3,766 & 1,267 & 4,000 & 3,533 & 2,833 & 1,700 & 5,967 \\
\hline & $\mathrm{C}$ & $5,823 a$ & 7,966 & 5,733 & 8,033 & 5,400 & 4,700 & 5,833 & 6,633 & 4,766 & 3,200 & 0,433 \\
\hline & $A$ & $2,953 a$ & 5,000 & 2,600 & 8,400 & 2,133 & 0,800 & 0,400 & 5,100 & 3,500 & 1,166 & 0,266 \\
\hline \multirow[t]{2}{*}{ Sabor de leite } & B & $3,533 a$ & 5,933 & 3,660 & 6,600 & 5,000 & 0,500 & 4,433 & 6,533 & 1,133 & 1,266 & 0,600 \\
\hline & C & $2,210 \mathrm{~b}$ & 3,300 & 1,733 & 1,400 & 2,900 & 0,366 & 5,700 & 3,333 & 2,633 & 0,133 & 8,366 \\
\hline Sabor farinha & A & $5,233 a$ & 2,033 & 5,200 & 6,167 & 5,600 & 2,867 & 6,166 & 6,667 & 6,433 & 2,833 & 1,333 \\
\hline \multirow[t]{2}{*}{ de trigo } & B & & 0,467 & 1,733 & 0,500 & 1,366 & 0,967 & 4,233 & 3,900 & 1,166 & 0,766 & 3,300 \\
\hline & C & $2,726 b$ & 0,667 & 2,900 & 8,333 & 1,366 & 2,333 & 1,533 & 2,567 & 3,266 & 1,000 & 0,700 \\
\hline \multirow{3}{*}{ Sabor salgado } & $\bar{A}$ & $2,796 a$ & 4,533 & 0,466 & 8,000 & 3,933 & 1,133 & 2,933 & 1,700 & 3,166 & 1,400 & 4,866 \\
\hline & B & $2,79 a$ & 0,867 & 5,200 & 2,666 & 1,966 & 1,433 & 4,833 & 2,533 & 1,900 & 1,633 & 1,566 \\
\hline & C & $193 a$ & 2,300 & 0,466 & 8,266 & 1,700 & 0,266 & 2,766 & 4,800 & 0,666 & 2,133 & 1,966 \\
\hline \multirow{3}{*}{ Sabor torrado } & A & $0,940 \mathrm{c}$ & 0,100 & 0,000 & 0,433 & 0,533 & 1,433 & 1,600 & 1,400 & 0,633 & 1,300 & 5,500 \\
\hline & B & $2,773 b$ & 0,133 & 0,000 & 2,000 & 1,233 & 2,200 & 4,300 & 5,700 & 2,966 & 3,700 & 7,033 \\
\hline & $\mathrm{C}$ & $4,480 \mathrm{a}$ & 0,466 & 1,500 & 8,600 & 5,400 & 2,633 & 5,633 & 6,063 & 4,600 & 2,867 & 7,966 \\
\hline \multirow{3}{*}{ Sabor de avelã } & $A$ & $2,223 a$ & 4,633 & 0,000 & 0,433 & 0,000 & 0,033 & 0,000 & 3,066 & 6,066 & 0,033 & 0,766 \\
\hline & B & $0,760 \mathrm{~b}$ & 6,267 & 0,000 & 0,500 & 0,000 & 0,033 & 0,000 & 0,000 & 0,000 & 0,033 & 0,533 \\
\hline & C & & 2,233 & 0,000 & 0,233 & 0,000 & 0,033 & 0,000 & 0,000 & 0,000 & 0,300 & 0,100 \\
\hline \multirow{3}{*}{$\begin{array}{l}\text { Sabor de } \\
\text { gordura vegetal }\end{array}$} & $A$ & $0,456 b$ & 0,900 & 1,100 & 0,233 & 0,600 & 0,033 & 0,000 & 1,000 & 0,000 & 0,067 & 0,100 \\
\hline & B & $0,840 \mathrm{~b}$ & 0,567 & 1,866 & 0,400 & 2,333 & 0,233 & 0,000 & 2,833 & 0,000 & 1,633 & 0,100 \\
\hline & C & & 3,133 & 5,033 & 0,566 & 3,400 & 0,300 & 0,000 & 4,466 & 0,000 & 3,400 & 2,200 \\
\hline \multirow{3}{*}{$\begin{array}{l}\text { Resistência à } \\
\text { mordida }\end{array}$} & $A$ & $3,033 b$ & 5,267 & 2,800 & 3,133 & 2,533 & 2,433 & 4,766 & 2,833 & 0,966 & 1,700 & 2,200 \\
\hline & B & $1,283 c$ & 1,600 & 1,433 & 0,300 & 1,400 & 1,300 & 1,733 & 1,533 & 0,733 & 6,100 & 1,100 \\
\hline & C & $6,423 a$ & 8,933 & 5,166 & 8,666 & 6,100 & 7,033 & 6,966 & 4,133 & 4,133 & 4,900 & 7,000 \\
\hline \multirow{3}{*}{ Crocância } & $A$ & $4,706 \mathrm{~b}$ & 8,133 & 3,300 & 6,400 & 3,666 & 5,000 & 3,600 & 3,666 & 4,300 & 4,900 & 4,100 \\
\hline & $\mathrm{R}$ & $5,506 a$ & 8,367 & 5,066 & 8,466 & 4,433 & 5,033 & 3,366 & 5,500 & 3,100 & 5,700 & 2,633 \\
\hline & C & & 6,067 & 1,366 & 0,133 & 1,700 & 1,767 & 1,500 & 2,366 & 1,933 & 2,066 & 6,033 \\
\hline \multirow{3}{*}{ Dissolução } & A & $4,986 a$ & 8,267 & 2,600 & 7,700 & 4,966 & 5,700 & 3,166 & 3,366 & 5,100 & 4,766 & 4,233 \\
\hline & B & $5,756 a$ & 8,533 & 2,600 & 8,566 & 5,966 & 6,167 & 4,333 & 5,366 & 5,400 & 5,566 & 5,066 \\
\hline & C & & 3,200 & 1,133 & 0,400 & 2,833 & 2,133 & 2,066 & 1,466 & 1,833 & 2,566 & 1,700 \\
\hline \multirow{3}{*}{$\begin{array}{l}\text { Arenosidade } \\
\text { recheio }\end{array}$} & A & $1,933 b$ & 1,333 & 2,766 & 0,300 & 0,433 & 0,166 & 2,500 & 2,560 & 1,433 & 0,266 & 0,166 \\
\hline & B & $0,893 b$ & 1,433 & 1,566 & 0,533 & 0,433 & 0,066 & 2,066 & 1,600 & 0,800 & 0,266 & 0,166 \\
\hline & C & $5,283 a$ & 6,533 & 3,800 & 8,633 & 2,966 & 2,966 & 5,700 & 5,700 & 3,966 & 4,333 & 8,233 \\
\hline
\end{tabular}




\subsubsection{Perfil Sensorial das Amostras}

Os perfis sensoriais de cada biscoito recheado sabor chocolate estão expressos nas Figuras 4, 5, 6 e 7. O centro das figuras representa 0 ponto zero da escala do atributo, enquanto a intensidade aumenta do centro para a periferia da figura. A média de cada atributo é marcada no eixo correspondente e o Perfil Sensorial traçado pela conexão dos pontos. Estes resultados são complementados pela Tabela 2 que fornece as médias obtidas pelas amostras em cada atributo e os resultados do Teste de Tukey.

Como pode ser observado na Figura 4, os biscoitos A e B não apresentam diferença quanto à cor do recheio que é bem mais intensa que a da amostra de biscoito $\mathrm{C}$.

Quanto à uniformidade da cor, o gráfico sugere maior intensidade deste atributo para o biscoito $A$, sendo que as outras duas amostras apresentaram menor intensidade e praticamente não diferiram entre si. Nos demais atributos, as três amostras parecem diferir entre si, sendo que o biscoito $\mathrm{C}$ apresentou cor creme mais intensa, maior quantidade de recheio e maior espessura da base. Estas observações foram confirmadas pelos testes ANOVA e Tukey (Tabela 2).

A análise do aroma das amostras baseou-se em 5 atributos: aromas de baunilha, cacau, manteiga, torrado e farinha. A Figura 5 mostra que 0 biscoito A apresentou menor intensidade de aromas de baunilha, de manteiga e de torrado e maior intensidade de aroma de farinha com relação às demais amostras. $O$ biscoito $B$ apresentou maior intensidade de aroma de cacau. Por outro lado, o biscoito $C$ apresentou maior intensidade de aromas de baunilha, de manteiga e de torrado e menor intensidade de aroma de cacau. Os testes ANOVA e Tukey mostram que os três biscoitos diferem entre si quanto aos aromas de baunilha, manteiga e torrado. Os biscoitos $\mathrm{A}$ e $\mathrm{C}$ apresentaram igual intensidade de aroma de cacau, sendo mais fracos que o B. O biscoito A apresentou aroma de farinha mais forte e significativamente diferente dos demais.

A Figura 6 revela que as amostras de biscoito A e B apresentaram características semelhantes quanto aos sabores de cacau, de manteiga e de leite e quanto ao sabor residual de gordura. $\mathrm{O}$ biscoito $\mathrm{C}$ apresentou características bem diferentes das demais amostras com relação aos sabores de cacau e de manteiga, sendo fraco em cacau e forte em manteiga. Quanto aos sabores de baunilha, de farinha e de assado, o 
FIGURA 4 - REPRESENTAÇÃO GRÁFICA DOS RESULTADOS DA ANÁLISE DESCRITIVA QUANTITATIVA (ADQ) PARA OS ATRIBUTOS DE APARÊNCIA DAS AMOSTRAS DE BISCOITO RECHEADO SABOR CHOCOLATE

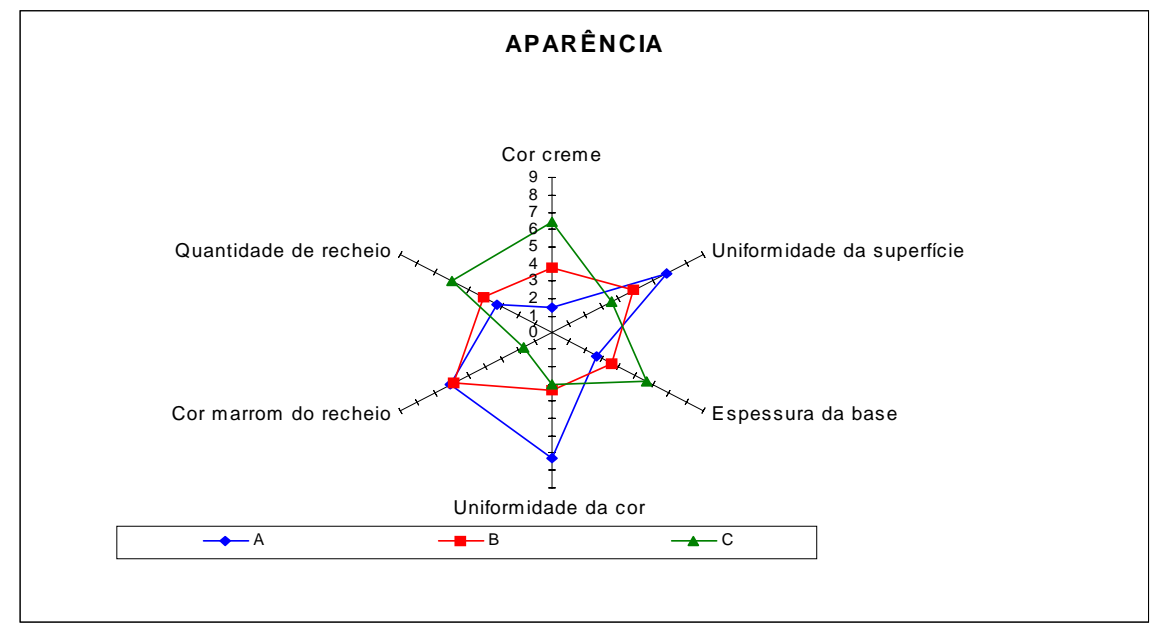

FIGURA 5 - REPRESENTAÇÃO GRÁFICA DOS RESULTADOS DA ANÁLISE DESCRITIVA QUANTITATIVA (ADQ) PARA OS ATRIBUTOS DE AROMA DAS AMOSTRAS DE BISCOITO RECHEADO SABOR CHOCOLATE

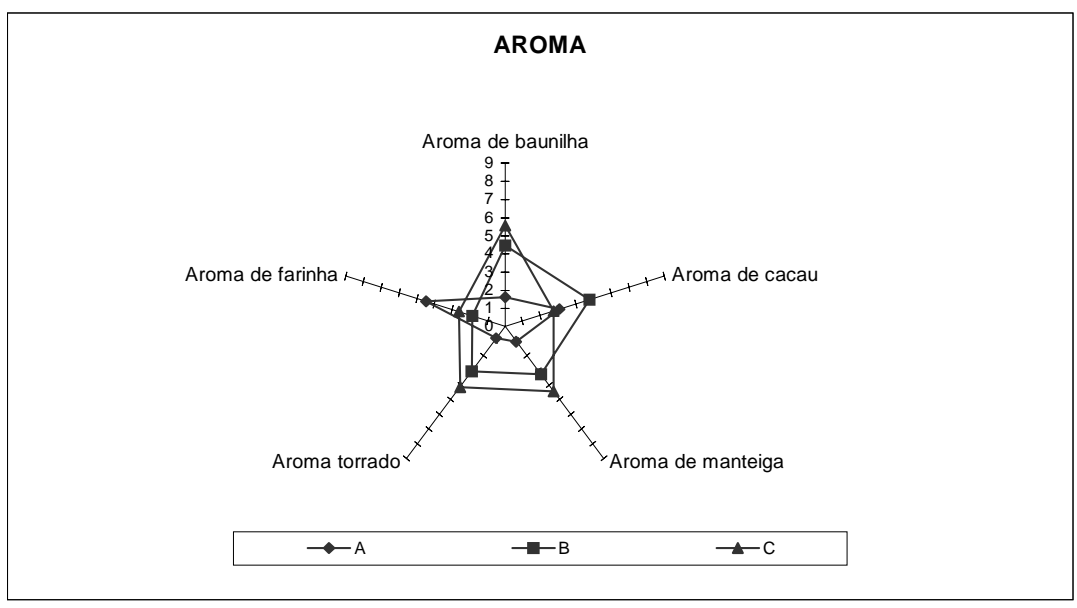


gráfico sugere que há diferença entre as amostras. Em relação ao sabor doce e de avelã, os biscoitos $B$ e $C$ parecem iguais. De fato, os testes ANOVA e Tukey confirmaram que A e B são semelhantes quanto aos sabores de cacau, manteiga, leite e gordura. Com relação aos sabores de baunilha, de farinha e assado, as três amostras diferiram entre si, sendo que o biscoito $\mathrm{C}$ caracterizou-se pelo forte sabor de baunilha, enquanto que o A apresentou sabor fraco de assado e, conseqüentemente, forte sabor de farinha. Os testes estatísticos confirmaram a semelhança entre os biscoitos $\mathrm{B}$ e $\mathrm{C}$ no que diz respeito aos atributos sabor doce e sabor de avelã.

\section{FIGURA 6 - REPRESENTAÇÃO GRÁFICA DOS RESULTADOS DA ANÁLISE DESCRITIVA QUANTITATIVA (ADQ) PARA OS ATRIBUTOS DE SABOR DAS AMOSTRAS DE BISCOITO RECHEADO SABOR CHOCOLATE}

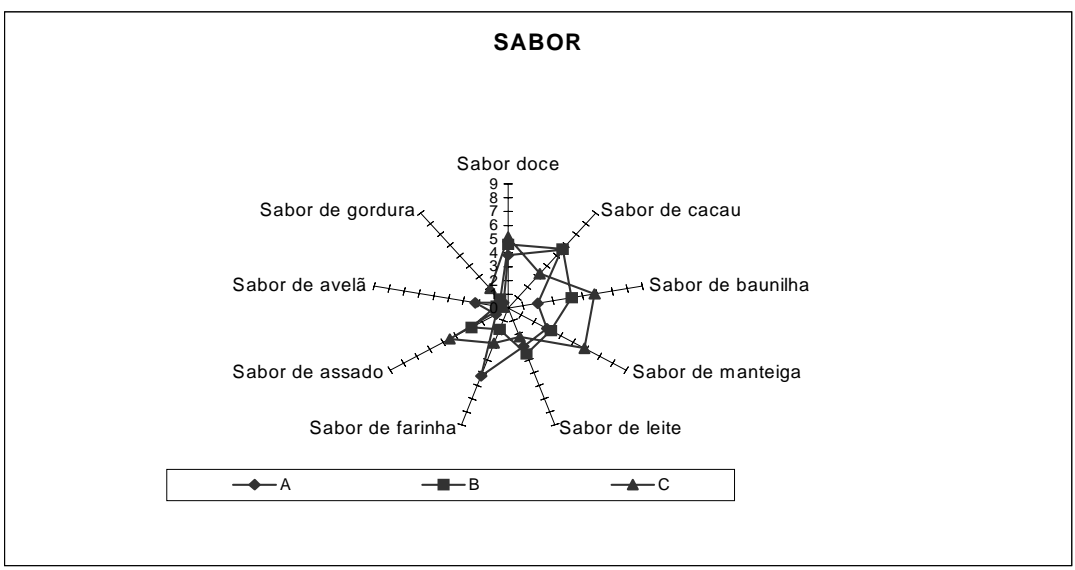

Os resultados da análise de textura sugerem que o biscoito $B$ apresenta maior crocância e dissolução, o seu recheio é menos arenoso e, também, oferece menor resistência à mordida. Aparentemente, o biscoito $\mathrm{A}$ apresentou características semelhantes às do B. Por outro lado, o biscoito $C$ revelou características bem diferentes dos outros dois, sendo menos crocante, com pouca dissolução, alta resistência à mordida e alta arenosidade do recheio, resultados confirmados pelos testes ANOVA e Tukey. 
Os testes estatísticos indicaram que as três amostras diferem entre si em relação à resistência à mordida e à crocância. $\mathrm{O}$ biscoito $\mathrm{B}$ é $\mathrm{O}$ menos resistente à mordida e o mais crocante. Quanto à dissolução e à arenosidade do recheio, os biscoitos $\mathrm{A}$ e $\mathrm{B}$ não diferiram entre si.

\section{FIGURA 7 - REPRESENTAÇÃO GRÁFICA DOS RESULTADOS DA ANÁLISE DESCRITIVA QUANTITATIVA (ADQ) PARA OS ATRIBUTOS DE TEXTURA DAS AMOSTRAS DE BISCOITO RECHEADO SABOR CHOCOLATE}

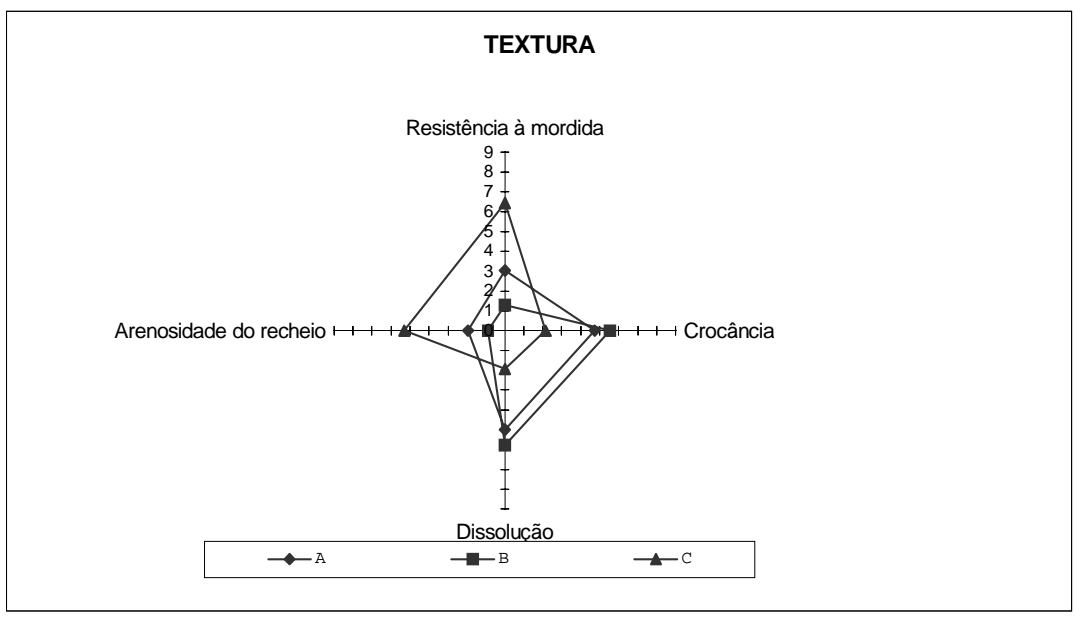

Quando os dados coletados neste trabalho foram submetidos à Análise Multivariada de Componentes Principais (ACP), as similaridades e diferenças existentes entre as amostras foram reveladas de forma bastante marcante, sendo evidenciadas claramente as propriedades sensoriais de cada amostra (Figuras 8, 9, 10 e 11). Na ACP, amostras similares ocupam regiões próximas no gráfico e são caracterizadas pelos vetores (atributos) que se apresentam mais próximos. Os resultados da ACP para os atributos de aparência, aroma, sabor e textura confirmaram os resultados baseados na interpretação dos gráficos apresentados nas Figuras 4, 5, 6 e 7 e nas análises estatísticas ANOVA e Tukey (Tabela 2). 
FIGURA 8- PROJEÇÃO DOS ATRIBUTOS SENSORIAIS DE APARÊNCIA (VETORES) E AMOSTRAS NOS COMPONENTES PRINCIPAIS I E II (ACP)

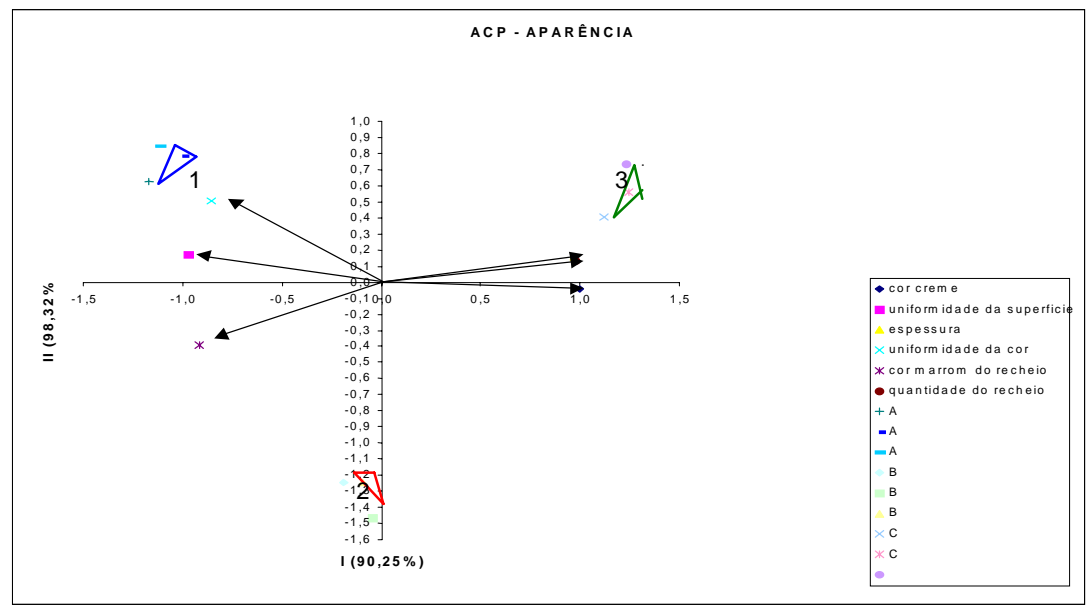

FIGURA 9 - PROJEÇÃO DOS ATRIBUTOS SENSORIAIS DE AROMA (VETORES) E AMOSTRAS NOS COMPONENTES PRINCIPAIS I E II (ACP)

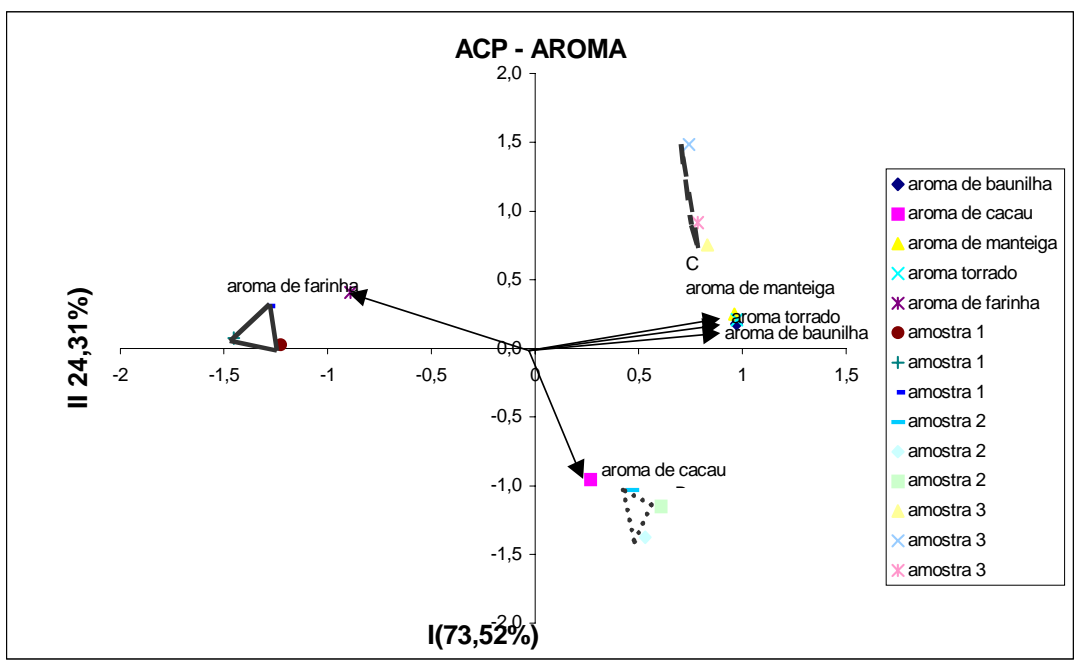


FIGURA 10 - PROJEÇÃO DOS ATRIBUTOS SENSORIAIS DE SABOR (VETORES) E AMOSTRAS NOS COMPONENTES PRINCIPAIS I E II (ACP)

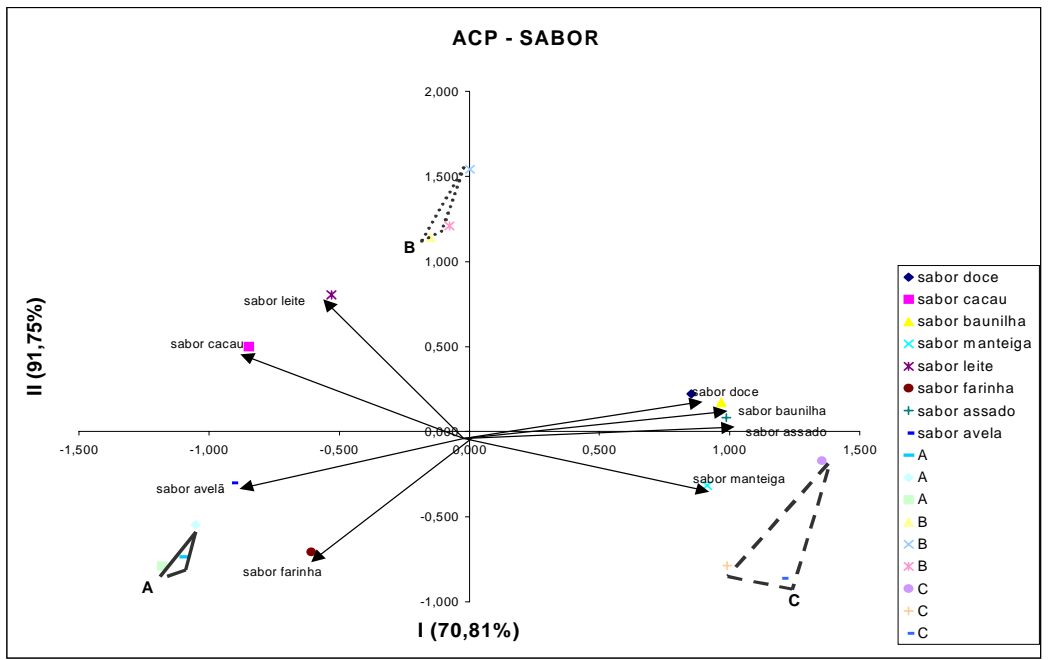

FIGURA 11 - PROJEÇÃO DOS ATRIBUTOS SENSORIAIS DE TEXTURA (VETORES) E AMOSTRAS NOS COMPONENTES PRINCIPAIS I E II (ACP)

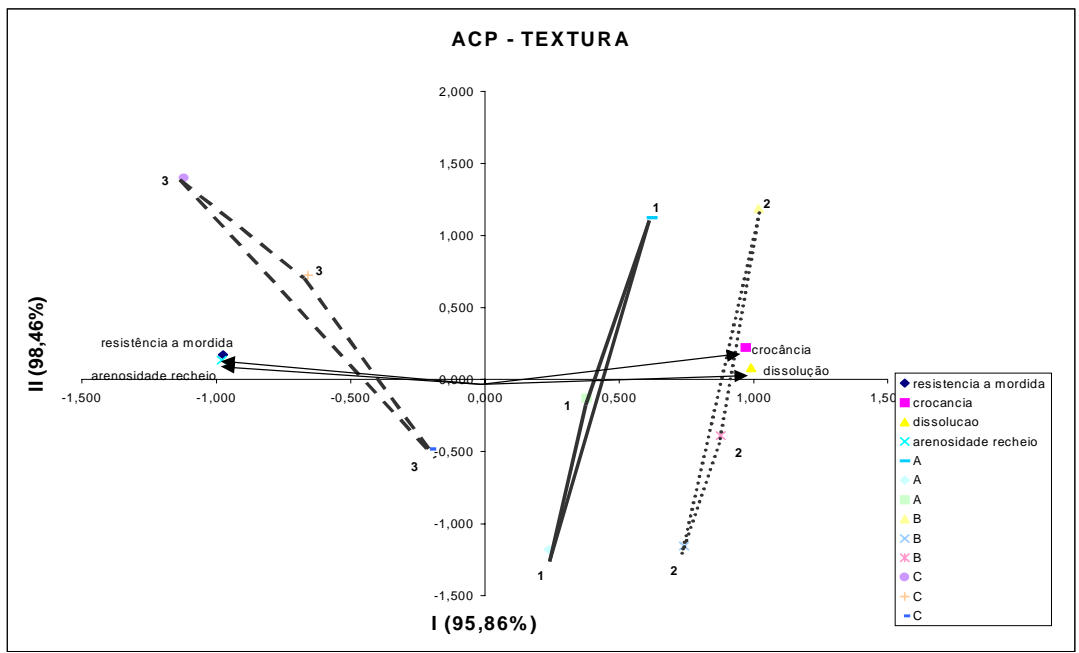


A reação dos provadores quanto à aceitação global, escala do ideal para resistência à mordida e intenção de compra pode ser observada nas Figuras 12, 13 e 14.

Quanto à aceitação global do produto (Figura 12), o biscoito $B$ foi o que apresentou melhor aceitação. Acima de $97 \%$ dos provadores gostaram do produto (soma das notas 6, 7, 8 e 9 do Teste de Aceitação - Figura 2 ), sendo que $40,5 \%$ gostaram muito e $31,0 \%$ adoraram. Apenas um provador $(2,4 \%)$ não gostou da amostra.

FIGURA 12 - ACEITAÇÃO GLOBAL DOS BISCOITOS RECHEADOS SABOR CHOCOLATE

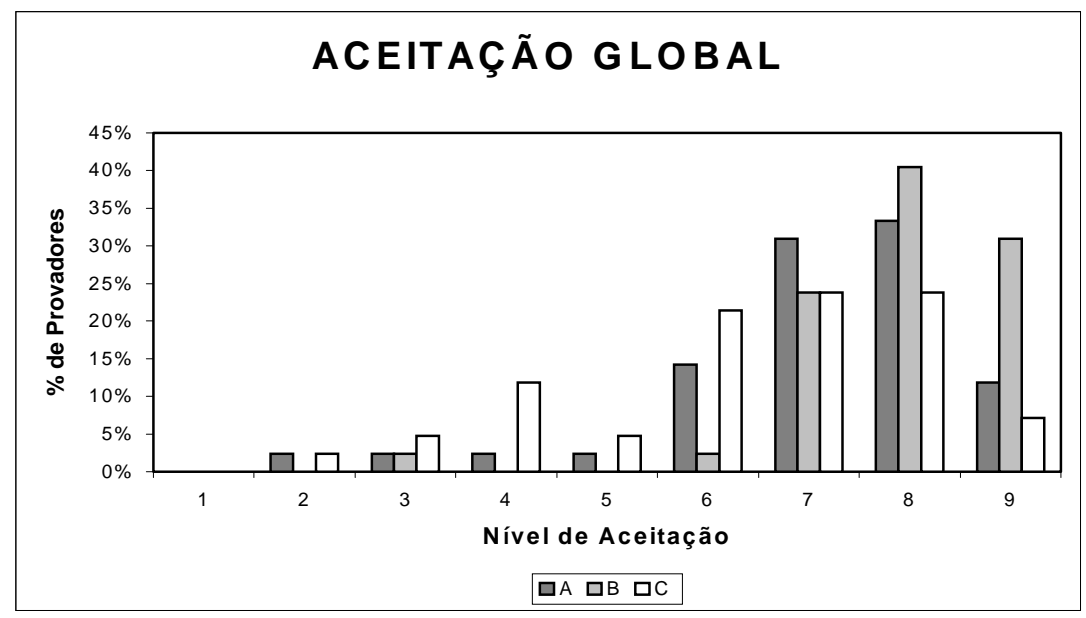

No caso do biscoito A, cerca de $90 \%$ dos provadores gostaram do produto, $45 \%$ gostaram muito e $11 \%$ gostaram muitíssimo. Três provadores $(7,1 \%)$ não gostaram deste biscoito.

A aceitação global do biscoito C foi a menor (76\% provadores), sendo que apenas $30 \%$ dos provadores gostaram muito ou muitíssimo da amostra. Oito provadores (19\%) não gostaram do biscoito.

Os resultados da Análise de Variância (Tabela 3) demonstraram que as 
três amostras de biscoito recheado sabor chocolate diferiram significativamente ao nível de $5 \%$ no que diz respeito à aceitação. $O$ biscoito B foi o que apresentou maior média com aceitabilidade próxima de "gostei muito" enquanto o biscoito $\mathrm{C}$ teve aceitabilidade entre "gostei ligeiramente" e "moderadamente".

\section{TABELA 3 - MÉDIAS DE ACEITAÇÃO}

\begin{tabular}{lll}
\hline Produto & Média & F(amostra) \\
\hline B & $7,88 \mathrm{a}$ & $16,17^{*}$ \\
A & $7,09 \mathrm{~b}$ & \\
C & $6,40 \mathrm{c}$ & \\
\hline
\end{tabular}

* Significativo ao nível de 5\%.

Com relação à resistência à mordida, o biscoito $\mathrm{B}$ obteve bons resultados, sendo considerado ideal por, aproximadamente, $50 \%$ dos provadores. Para o biscoito A este percentual diminuiu para $38 \%$. Por outro lado, a resistência à mordida do biscoito $\mathrm{C}$ foi considerada ideal por somente $18 \%$ dos provadores e moderadamente abaixo da ideal por $55 \%$.

FIGURA 13 - ESCALA DO IDEAL PARA RESISTÊNCIA À MORDIDA

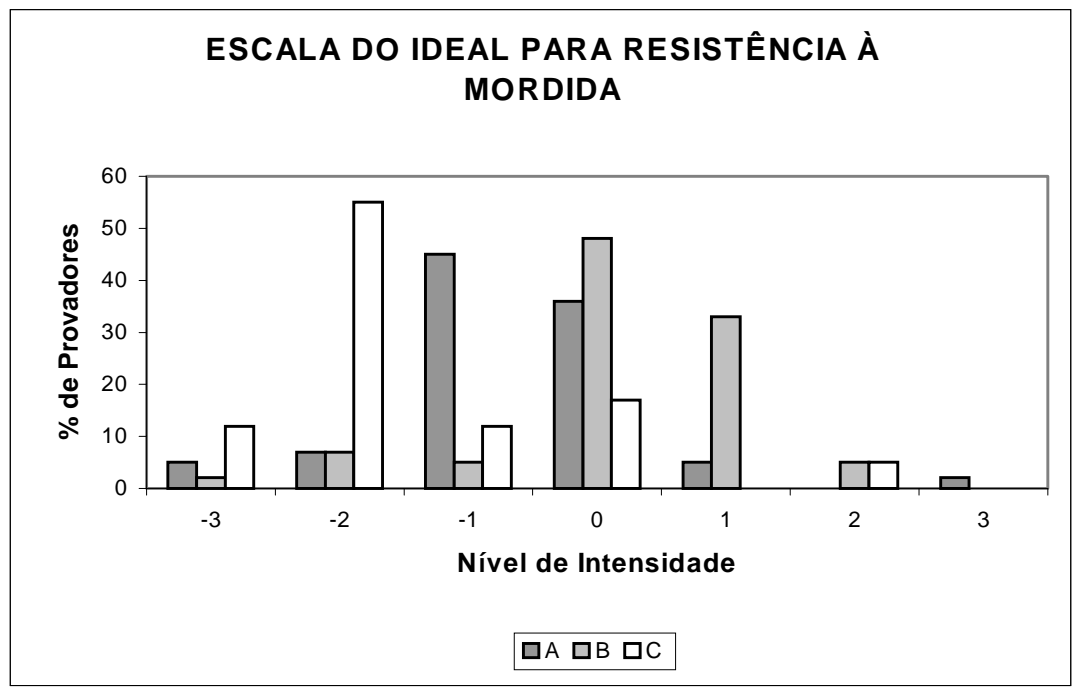


Como pode ser observado na Figura 14, o biscoito B alcançou $91 \%$ das intenções de compra contra $67 \%$ do biscoito A (soma das notas 4 e 5 do Teste de Aceitação - Figura 2). O biscoito $C$ não apresentou bons resultados, pois apenas $33 \%$ dos provadores comprariam o produto.

\section{FIGURA 14 - INTENÇÃO DE COMPRA}

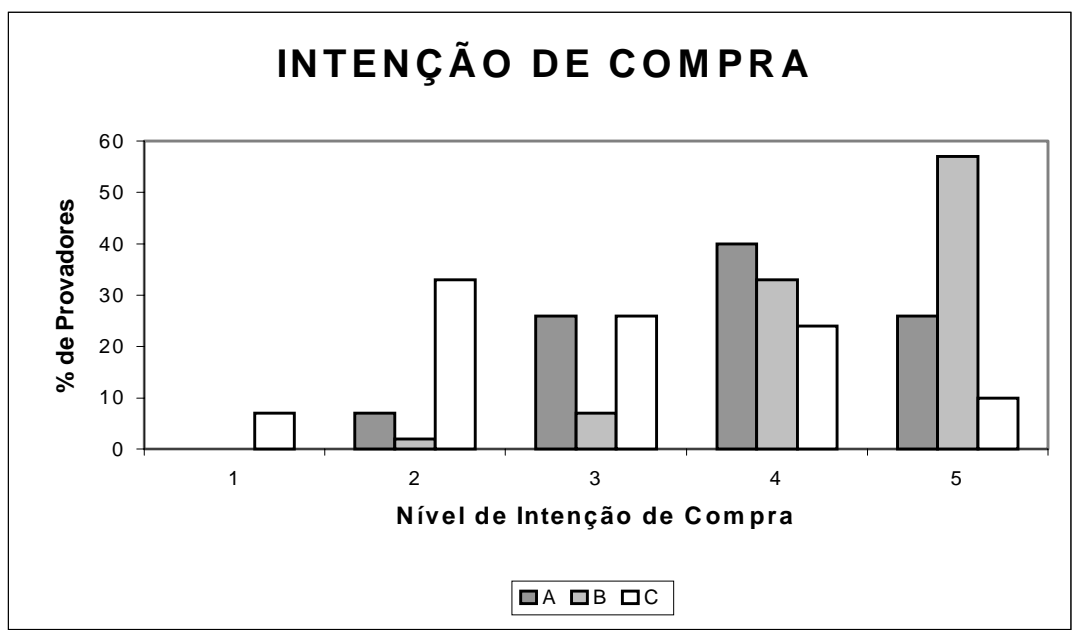

\section{CONCLUSÃO}

Pode-se concluir que os biscoitos que competem em mesmo nível no mercado são muito distintos entre si no que diz respeito às suas características sensoriais. O biscoito $B$ foi o que apresentou melhor aceitação pelos consumidores evidenciando que atributos como aroma e sabor de cacau, crocância, baixa arenosidade do recheio, boa dissolução e pouca resistência à mordida são características bastante importantes para a determinação da preferência no mercado.

\section{Abstract \\ SENSORIAL PROFILE AND STUFFED COOKIES WITH CHOCOLATE FLAVOR CONSUMER TEST}

The objective of this work was to construct sensory profiles of three commercial brands of stuffed cookies with chocolate flavor, leaders in the consumer market. Quantitative Descriptive Analysis (QDA) was employed to evaluate the sensorial attributes of products 
and consumer test to verify which attributes determines its acceptation and preference in the market. It was concluded that the samples, which compete in the market, are sensorially very different. The cookie that presented better acceptance by consumers evidenced that the attributes as aroma and cacao flavor, crunchiness, low sandiness of stuffing, good dissolution and low bite resistance, are very important characteristics for the market preference.

KEY-WORDS: COOKIES; QUANTITATIVE DESCRIPTIVE ANALYSIS; SENSORIAL ANALYSIS.

\section{REFERÊNCIAS}

1 BROWN, W.E.; LANGLEY, K.R.; BRAXTON, D. Insight into consumers' assessments of biscuit texture based on mastication analysis - hardness versus crunchiness. Journal of Texture Studies, v. 29, p. 481-497, 1998.

2 GOYLE, A.; GUJRAL, S. Sensory evaluation of and acceptability trials on biscuits prepared from raw and malted wheat (Triticum aestivum)- Bengal gram (Cicer arietinum) mixes with or without a green leafy vegetable. Plants Foods for Human Nutrition, v. 42, p. 291-296, 1992.

3 MANOHAR, R.S.; RAO, P.H. Effect of sugars on the rheological characteristics of biscuit dough and quality of biscuits. J. Sci. Food Agric., v. 75, p. 383-390, 1997.

4 MEILGAARD, G.K.; CIVILLE, G.V.; CARR, B.I. Sensory evaluation techniques. Florida: CRC Press, 1991. $281 \mathrm{p}$.

5 MOSKOWITZ, H. R. Product testing and sensory evaluation of foods: marketing and R \& D approaches. Westport: Food \& Nutrition Press, 1983. $605 \mathrm{p}$.

6 SAS Institute Inc. Statistic analyses systems (SAS). Cary, USA, 1985. (Version 6.12.)

7 STONE, H.J.; SIDEL, J.L. Sensory evaluation practices. London: Academic Press, 1993. Cap. 6, p. 202-226. 